\title{
Intra-guild vs extra-guild prey: effect on predator fitness and preference of Amblyseius swirskii (Athias-Henriot) and Neoseiulus cucumeris (Oudemans) (Acari: Phytoseiidae)
}

\author{
R. Buitenhuis ${ }^{1,2}$, L. Shipp ${ }^{2 *}$ and C. Scott-Dupree ${ }^{1}$ \\ ${ }^{1}$ Department of Environmental Biology, University of Guelph, Guelph, \\ ON, N1G 2W1, Canada: ${ }^{2}$ Greenhouse and Processing Crops Research \\ Centre, Agriculture and Agri-Food Canada, 2585 County Rd 20, Harrow, \\ ON, N0R 1G0, Canada
}

\begin{abstract}
The relationships between the predatory mites, Amblyseius swirskii (AthiasHenriot) and Neoseiulus cucumeris (Oudemans) (Acari: Phytoseiidae), and their prey, western flower thrips (Frankliniella occidentalis Pergande) (Thysanoptera: Thripidae), were investigated to determine the effects of predation on intra-guild or extra-guild prey and predator preference. Life history characteristics of both predatory mites were measured when fed eggs and larvae of the other predator species and compared to data obtained when the predators were fed thrips larvae. In addition, choice tests were conducted to determine if the predators had a preference for different prey or if they were indiscriminate predators. Amblyseius swirskii appears to be an important intra-guild predator of N. cucumeris juveniles because of a high predation rate and a preference for N. cucumeris juveniles over thrips. Neoseiulus cucumeris is also an intra-guild predator of $A$. swirskii juveniles; however, it has a lower predation rate than $A$. swirskii. Contrary to intra-guild predation theory, intraguild prey was an equally good or better food source than thrips (extra-guild prey) for both predators, based on high oviposition rates and fast development times. The results of this study indicate a high potential for negative interactions between A. swirskii and N. cucumeris when used together in biological control of thrips.
\end{abstract}

Keywords: Phytoseiidae, fitness, prey preference, intra-guild interactions, extraguild prey, biological control

(Accepted 16 March 2009)

\section{Introduction}

Pest suppression in greenhouse crops is often accomplished using several species of natural enemies simultaneously for the control of one or more pests. This practice

*Author for correspondence

Fax: 519-738-2929

E-mail: shippl@agr.gc.ca leads to the creation of artificial food webs where plants, pests and natural enemies engage in complex food web interactions (Janssen et al., 1998). Many biological control agents interact because they have overlapping food ranges and compete for the same food source. In addition, they also are likely to engage in intra-guild interactions with each other. This may or may not have an effect on pest density and, hence, influence pest control (e.g. Rosenheim et al., 1995; Finke \& Denno, 2003; Prasad \& Snyder, 2004; Rosenheim \& Harmon, 2006). Food webs with multiple intra-guild 
predator species have been shown to be far less effective at suppressing herbivores than webs consisting largely of strict predators (Denno \& Finke, 2006). Intra-guild interactions may especially occur when pest densities are low (Polis et al., 1989), such as in greenhouse ornamentals where pest tolerance is very low.

Amblyseius swirskii (Athias-Henriot) (Acari: Phytoseiidae) is a relatively new predator used for whitefly and thrips control in greenhouse crops (Nomikou et al., 2001; Messelink et al., 2006). It is a generalist predator preying on many insect and mite species and also feeding on pollen. This broad host range is advantageous because $A$. swirskii could be used to control multiple pest species in the greenhouse, as is the case for many generalist predators (Symondson et al., 2002). In addition, $A$. swirskii populations increase much faster, and pest control is better, when two different prey species (whiteflies and thrips) are available, as compared to only one of the two prey species (Messelink et al., 2008). However, a broad host range could also be a problem if $A$. swirskii is preying on other biological control agents in the greenhouse ecosystem, such as Aphidoletes aphidimyza eggs or other predatory mite species. Amblyseius swirskii potentially is able to do so, because it has been shown to feed on protonymphs of the phytoseiid predatory mite Euseius scutalis (AthiasHenriot) (Rasmy et al., 2004). In addition, there is ample evidence of related generalist phytoseiid mites feeding on other phytoseiids (McMurtry \& Croft, 1997) and generalist phytoseiid mites being more aggressive intra-guild predators of heterospecific phytoseiid mites than specialists (Schausberger \& Croft, 2000).

In many greenhouse crops, e.g. peppers, cucumber and gerbera, growers release both $A$. swirskii and Neoseiulus cucumeris (Oudemans) (Acari: Phytoseiidae). Although A. swirskii might to be superior for thrips control to $N$. cucumeris according to some studies (van Houten et al., 2005; Messelink et al., 2006), there are still too many unknown factors to decide which predator is the best. One of the reasons for releasing $A$. swirskii and N. cucumeris together is because $N$. cucumeris is less expensive as it is easily mass reared. Growers release N. cucumeris at the beginning of the crop and later add $A$. swirskii. There are indications that both species indeed interact negatively with each other. For example, it has been observed that plots of greenhouse cucumber to which $N$. cucumeris had been applied were accidentally colonized by $A$. swirskii, resulting in total elimination of the N. cucumeris population (Messelink et al., 2005).

It is not known if $A$. swirskii has intra-guild interactions with $N$. cucumeris, or vice versa, and if so, what the predation rate is. In contrast to many intra-guild interactions where there is an intra-guild predator and and intra-guild prey, A. swirskii and N. cucumeris potentially engage in symmetrical (mutual) intra-guild predation where adults of each species are eating juveniles of the competing species (Polis et al., 1989; Polis \& Holt, 1992). Intra-guild interactions are likely to be more important if the quality of intra-guild prey as a food source is high, leading to a higher fitness, and if the predator has a preference for intra-guild prey. Therefore, in this study, we investigated (i) fitness parameters, such as oviposition rate, predation rate and development time, of $A$. swirskii and $N$. cucumeris when fed intra-guild or extra-guild prey (Frankliniella occidentalis (Pergande)); and (ii) A. swirskii and N. cucumeris prey preference in choice experiments.

\section{Material and methods}

\section{Thrips and predatory mite rearing}

A greenhouse colony of western flower thrips, F. occidentalis, was maintained on yellow potted chrysanthemum (Dendranthema grandiflora Tzvelev, var. Chesapeake). Cohorts of thrips larvae were reared on kidney bean (Phaseolus vulgaris L.) leaves embedded in 1.5\% (w/v) agar in 9-cm Petri dishes with thrips-proof screened lids in a controlled environmental chamber $\left(25^{\circ} \mathrm{C} \pm 1\right.$, RH $70 \pm 10 \%$, $\mathrm{L}: \mathrm{D} 12: 12)$. Twenty-five female thrips were allowed to oviposit on the leaf for two days. First instar larvae were obtained after four days (Robb, 1989).

Laboratory colonies of predatory mites were established using A. swirskii and N. cucumeris from Biobest Canada Ltd (Leamington, ON, Canada). Amblyseius swirskii was reared according to methods adapted from Overmeer (1985) on kidney bean leaf disks that were placed upside down on water saturated sponges in 237-ml containers (Solo, Highland Park, IL, USA), which were closed with a fine mesh $(100 \mu \mathrm{m}$ mesh opening) screened lid. Mites were fed with cattail pollen (Typha sp.) every other day. Pollen was field collected and stored in the freezer at $-15^{\circ} \mathrm{C}$. Eggs were collected every day to create cohorts of a known age $(<24 \mathrm{~h})$. A colony of N. cucumeris was fed on Tyrophagus putrescentiae (Schrank) (Acari: Acaridae) maintained on wheat bran. Neoseiulus cucumeris adult females were collected from the colony and held on bean leaf disks with cattail pollen. To obtain evenly aged mite cohorts, eggs were collected and reared on pollen as described above for A. swirskii.

\section{Predation and oviposition capacity}

To investigate the effects of eating intra- or extra-guild prey, A. swirskii and N. cucumeris females (2-4 days old) were provided with prey ad libitum for four days. Predation (number of prey individuals consumed) and oviposition capacity (number of eggs laid) of both predatory mite species were measured when fed eggs, larvae or deutonymphs of the other predatory mite species and compared to data obtained when the predatory mites were fed first instar thrips larvae. One female predatory mite was confined on a leaf disk $(1.5 \times 1.5 \mathrm{~cm})$ that floated upside down on a water saturated sponge in a $60-\mathrm{ml}$ cup (Solo, Highland Park, IL, USA). The cup was closed with fine mesh $(100 \mu \mathrm{m}$ mesh opening) screening held in place by a plastic lid with a 2-cm diameter opening. Cups were placed in a controlled environmental chamber $\left(25^{\circ} \mathrm{C} \pm 1, \mathrm{RH} 70 \pm 10 \%, \mathrm{~L}: \mathrm{D} 16: 8\right)$. Prey was renewed every day (10 eggs, 15 larvae, 10 deutonymphs, 10 first instar thrips). Trials were replicated 8-15 times. Data from the first day were omitted from the calculations of predation and oviposition capacity to reduce the influence of pre-experimental conditions (van Houten et al., 1995).

\section{Development time and survival to adult stage}

The influence of different intra-guild and extra-guild prey on predatory mite development time was investigated for both $A$. swirskii and N. cucumeris. Eggs of either species $(<12 \mathrm{~h}$ old) were individually placed on bean leaf disks such as were used in the previous experiments. Every 12 hours, eggs were checked for hatching. After hatching, the immature predatory mites were provided with prey ad libitum every 12 hours, either intra-guild predatory mite eggs or 
Table 1. Daily predation rate (mean $\pm \mathrm{SE}$ ) of Amblyseius swirskii and Neoseiulus cucumeris on western flower thrips, Frankliniella occidentalis, and intra-guild prey $(N=8-15)$.

\begin{tabular}{lcccc}
\hline & Thrips & \multicolumn{3}{c}{ Intra-guild prey } \\
\cline { 2 - 5 } & First instar larvae & Eggs & Larvae & Deutonymphs \\
\hline A. swirskii & $4.0 \pm 0.3 \mathrm{c}$ & $2.0 \pm 0.5 \mathrm{~b}$ & $11.4 \pm 0.3 \mathrm{~g}$ & $7.0 \pm 0.4 \mathrm{ef}$ \\
N. cucumeris & $5.8 \pm 0.8 \mathrm{de}$ & $0.7 \pm 0.1 \mathrm{a}$ & $7.8 \pm 0.3 \mathrm{f}$ & $4.5 \pm 0.3 \mathrm{~cd}$ \\
\hline
\end{tabular}

Values in columns and rows followed by different letters are significantly different $(\alpha<0.05)$.

larvae or first instar thrips larvae. Predatory mite prey were frozen in order to prevent the eggs from hatching and to be able to recognize experimental larvae from prey larvae. This did not seem to influence mite feeding (R. Buitenhuis, personal observation). First instar thrips were alive. During development, predatory mites were checked every 12 hours for moulting, recognized by the presence of an exuvium on the leaf disk and for survival. The experiment was replicated 16 times in two blocks of eight replicates.

\section{Choice experiments}

Two different choice tests were conducted to determine if the predators had a preference for any prey species, or life stage, or if they predated indiscriminately. In the first experiment (performed only with $A$. swirskii), female predatory mites were offered two types of prey ad libitum and the quantities of each prey eaten were measured. In the second experiment (performed with the two predator species), one individual of each of two types of prey were offered in choice tests.

In the first experiment, female $A$. swirskii (2-4 days old) were individually placed on bean leaf disks such as were used in the previous experiments and given abundant prey of the two prey species/stages for two days $(5 \mathrm{~N}$. cucumeris eggs $+15 \mathrm{~N}$. cucumeris larvae; $5 \mathrm{~N}$. cucumeris eggs +10 first instar thrips; $15 \mathrm{~N}$. cucumeris larvae +10 first instar thrips). Data from the first day were omitted to reduce the influence of pre-experimental conditions (van Houten et al., 1995). As an indiscriminate predator, it would be expected that the mite would eat half the amount of both prey types as measured in the experiment on predation capacity. It was not possible to perform the same experiment for $N$. cucumeris females because the $A$. swirskii larvae quickly molted to protonymphs which fed on the thrips and eggs, confounding the results. The treatments were replicated 15 times.

In the second experiment, female $A$. swirskii and N. cucumeris mites were observed when given the choice between one of each of two prey species/stages: between an egg or larva of the opposite predator species, an egg of the opposite predator species and a first instar thrips, or between a larva of the opposite predator species and a first instar thrips). A single female mite (2-4 days old) was given a 24 hour (day 1) exposure period to abundant prey of two prey species/stages and then starved for 24 hours (day 2). On the third day, the female was confined on a small bean leaf disk $(0.5 \times 0.5 \mathrm{~cm})$ with one of each of two prey species/stages and her behaviour was observed and timed until she made a choice and started feeding. Sample size varied between 11 and 13 replicates.

\section{Statistical analysis}

Predation and oviposition capacity data and development time were square root transformed to adjust the data for homogeneity of variance and normality, and comparisons were made among prey types and between predator species using two-way ANOVA. In the choice experiment, the numbers of prey eaten of both prey types were compared to the expected numbers of prey eaten (half the amount of both prey types as measured in the experiment on predation capacity) using a $t$-test for each combination of prey types. The results from the choice observations were compared using a chi-square test of goodness-of-fit, where the observed frequencies were compared to expected frequencies of 0.5 (no preference). For all statistical analyses, SAS statistical package ver. 9.1.3 was used and differences were determined to be significant at $\alpha<0.05$.

\section{Results \\ Predation and oviposition capacity}

Both A. swirskii and N. cucumeris preyed on immature stages of the opposite predator species (intra-guild prey) (table 1). However, they fed on eggs only in very small numbers. Adult stages did not feed on each other (R. Buitenhuis, personal observation). There were significant differences in predation rates between the two predatory mite species among different prey types (prey type: $\mathrm{F}_{3,78}=127.42, P<$ 0.0001; predator species $F_{1,78}=16.03, P<0.0001$ ), but the interaction between prey types and predator species was also significant $\left(F_{3,78}=7.69, P<0.0001\right)$, which means that the effects of both main effects were interrelated. Comparing the two predators, A. swirskii had a significantly higher predation rate of intra-guild prey (eggs, larvae and deutonymphs) than $N$. cucumeris, but $A$. swirskii consumed significantly less thrips than $N$. cucumeris (table 1). Oviposition rates were also significantly different among different prey types (prey type: $\mathrm{F}_{3,78}=13.10, P<0.0001$; predator species $\mathrm{F}_{1,78}=2.44, P=$ $0.1220)$, but the interaction between prey types and predator species was again significant $\left(\mathrm{F}_{3,78}=3.99, P=0.0106\right)$. Similar to the results of predation rate, $A$. swirskii had a higher oviposition rate on intraguild prey eggs and deutonymphs than $N$. cucumeris, but laid fewer eggs than $N$. cucumeris when it was fed on thrips (table 2). Comparing oviposition rates on different prey within species, $A$. swirskii laid more eggs when feeding on N. cucumeris larvae and deutonymphs than on thrips, which indicates that mite immatures are the better food source for this predator (table 2). In contrast, oviposition by N. cucumeris was the same on both thrips and A. swirskii immatures. Oviposition rates of both predator species on eggs were the lowest. 
Table 2. Daily oviposition rate (mean $\pm \mathrm{SE}$ ) of Amblyseius swirskii and Neoseiulus cucumeris on western flower thrips, Frankliniella occidentalis, and intra-guild prey $(\mathrm{N}=8-15)$.

\begin{tabular}{|c|c|c|c|c|}
\hline & \multirow{2}{*}{$\begin{array}{l}\text { Thrips } \\
\text { First instar larvae }\end{array}$} & \multicolumn{3}{|c|}{ Intra-guild prey } \\
\hline & & Eggs & Larvae & Deutonymphs \\
\hline A. swirskii & $1.4 \pm 0.2 \mathrm{bc}$ & $1.2 \pm 0.2 b$ & $2.1 \pm 0.1 \mathrm{e}$ & $2.1 \pm 0.2 \mathrm{e}$ \\
\hline N. cucumeris & $2.0 \pm 0.2 \mathrm{de}$ & $0.8 \pm 0.1 \mathrm{a}$ & $1.9 \pm 0.2 \mathrm{cde}$ & $1.5 \pm 0.2 \mathrm{bcd}$ \\
\hline
\end{tabular}

Values in columns and rows followed by different letters are significantly different $(\alpha<0.05)$.

Table 3. Duration of developmental stages in hours (mean $\pm \mathrm{SE}$ ) and percent survival until adulthood of $A$. swirskii and N. cucumeris on a diet of intra-guild (eggs or larvae) or extra-guild (first instar thrips larvae, Frankliniella occidentalis) prey $(N=16)$.

\begin{tabular}{|c|c|c|c|c|c|c|}
\hline Prey & \multicolumn{5}{|c|}{ Development time (h) } & Survival \% \\
\hline \multicolumn{7}{|l|}{ A. swirskii } \\
\hline N. cucumeris larvae & $42 \pm 3 \mathrm{ab}$ & $14 \pm 2 \mathrm{a}$ & $36 \pm 3$ a & $31 \pm 3$ a & $124 \pm 4 \mathrm{a}$ & 82 \\
\hline Thrips first instar & $41 \pm 2$ a & $17 \pm 2 \mathrm{ab}$ & $48 \pm 4 \mathrm{ab}$ & $48 \pm 8 b$ & $153 \pm 7 b$ & 62 \\
\hline \multicolumn{7}{|l|}{ N. cucumeris } \\
\hline Thrips first instar & $49 \pm 2$ bc & $18 \pm 2 \mathrm{ab}$ & $76 \pm 8 c$ & $40 \pm 9 a b$ & $182 \pm 13 c$ & 43 \\
\hline
\end{tabular}

Values in columns and rows followed by different letters are significantly different $(\alpha<0.05)$.

Table 4. F- and P-values of two-way ANOVAs analyzing the duration of each developmental stage separately for A. swirskii and $N$. cucumeris (predator species) on a diet of intra-guild or extra-guild prey (prey type) $(\alpha<0.05)$.

\begin{tabular}{|c|c|c|c|c|c|c|c|c|c|}
\hline \multirow[t]{2}{*}{ Life stage } & \multicolumn{3}{|c|}{ Predator species } & \multicolumn{3}{|c|}{ Prey type } & \multicolumn{3}{|c|}{ Interaction } \\
\hline & $\mathrm{F}$ & $P$ & $\mathrm{df}$ & $\mathrm{F}$ & $P$ & $\mathrm{df}$ & $\mathrm{F}$ & $P$ & $\mathrm{df}$ \\
\hline Egg & 12.68 & 0.0006 & 1,80 & 0.39 & 0.6764 & 2,80 & 0.61 & 0.5451 & 2,80 \\
\hline Protonymph & 10.02 & 0.0026 & 1,51 & 10.52 & 0.0001 & 2,51 & 1.76 & 0.1820 & 2,51 \\
\hline Deutonymph & 0.00 & 0.9715 & 1,37 & 2.28 & 0.1169 & 2,37 & 1.26 & 0.2967 & 2,37 \\
\hline
\end{tabular}

\section{Development time and survival to adult stage}

Total development time was faster for $A$. swirskii than for $N$. cucumeris $\left(\mathrm{F}_{1,80}=12.68, P=0.0006\right)$. For both predator species, there were also significant differences in development time depending on prey type $\left(F_{2,80}=0.39, P=0.6764\right)$, but no significant interaction occurred between predator species and prey type $\left(\mathrm{F}_{2,80}=0.61, P=0.5451\right)$. The difference in development time between $A$. swirskii and $N$. cucumeris was caused by significantly shorter $A$. swirskii egg and protonymph stages (table 3 ; see table 4 for $\mathrm{F}$ and $P$ values for each developmental stage). Differences among prey types are only observed for the protonymph stage of N. cucumeris.

Survival to the adult stage was very low (23\%) for A. swirskii fed on N. cucumeris eggs (table 3). It was observed that $A$. swirskii protonymphs that died were not able to feed on eggs. However, in the cases where A. swirskii protonymphs were able to pierce the eggs and consumed the contents, they survived to adults and development time was intermediate. Protonymphs of $N$. cucumeris were often unable to feed on $A$. swirskii eggs and thrips, also leading to a lower percentage of immatures surviving until the adult stage.

\section{Choice experiments}

In choice experiments with excess of the two prey types, A. swirskii predated more than expected on N. cucumeris larvae $(t=-6.48, P<0.0001)$ but killed the same number of thrips larvae as expected $(t=-0.60, P=0.5545)$ (table 5$)$. Eggs of $N$. cucumeris were preyed on as expected when combined with thrips (eggs: $t=-1.50, P=0.1449$; thrips: $t=-5.51, P<0.0001$ ) and N. cucumeris larvae (eggs: $t=0.99$, $P=0.3300$; larvae: $t=-9.06, P<0.0001$ ) both of which were killed more than expected in these prey combinations. The observations on prey choice (table 5) confirmed these results (egg vs thrips: $\chi^{2}=13.00, P=0.0003$; larva vs thrips: $\chi^{2}=5.33$, $P=0.0209$; egg vs larva: $\left.\chi^{2}=8.33, P=0.0039\right)$. In contrast, $N$. cucumeris had no preference between $A$. swirskii eggs and larvae $\left(\chi^{2}=0.69, P=0.4054\right)$ or $A$. swirskii eggs and thrips larvae $\left(\chi^{2}=1.92, P=0.1655\right)$. However, as in the case of A. swirskii, N. cucumeris preferred to prey on intra-guild prey larvae rather than on thrips larvae $\left(\chi^{2}=4.45, P=0.0348\right)$.

\section{Discussion}

Phytoseiid predatory mites are used worldwide in biological control of several different pests, such as thrips, 
Table 5. Predation rate (one day) of Amblyseius swirskii and Neoseiulus cucumeris presented with two prey species/stages (mean \pm SE), and separate trial on observations on prey choice (prey 1: prey 2).

\begin{tabular}{|c|c|c|c|}
\hline & \multicolumn{2}{|c|}{ Predation rate } & \multirow{2}{*}{$\begin{array}{l}\text { Observations } \\
\text { (prey1: prey2) }\end{array}$} \\
\hline & Prey 1 & Prey 2 & \\
\hline \multicolumn{4}{|l|}{ A. swirskii } \\
\hline N. cucumeris larvae vs thrips first instar & $9.1 \pm 0.5^{*}$ & $2.2 \pm 0.3 \mathrm{~ns}$ & $10: 2^{*}$ \\
\hline N. cucumeris eggs vs $N$. cucumeris larvae & $0.7 \pm 0.2 \mathrm{~ns}$ & $10.7 \pm 0.5^{*}$ & $1: 11^{*}$ \\
\hline \multicolumn{4}{|l|}{ N. cucumeris } \\
\hline A. swirskii eggs vs $A$. swirskii larvae & - & - & $4: 9 \mathrm{~ns}$ \\
\hline
\end{tabular}

${ }^{1} t$-test, compared to expected results (half of the predation rates in table 1 ). If $A$. swirskii is an indiscriminate predator, predation rates of prey 1 and 2 are not significant (ns). If $A$. swirskii shows a preference, prey 1 or 2 is significantly different $\left(^{*}\right) \alpha<0.05$.

2 Chi-square test of goodness of fit.

spider mites, broad and cyclamen mites and whiteflies (Helle \& Sabelis, 1985; McMurtry \& Croft, 1997). Interspecific predation and cannibalism have been demonstrated in several species of phytoseiid mites (e.g. Croft \& Croft, 1996; Croft et al., 1996; McMurtry \& Croft, 1997; Walzer \& Schausberger, 1998, 1999; Schausberger, 1999; Montserrat et al., 2006) and poses a potential problem when several of these predator species are used together in biological control. The results of this study demonstrate mutual intra-guild interactions between $A$. swirskii and $N$. cucumeris. The juvenile stages (larva to deutonymph) are especially vulnerable, but not eggs.

Contrary to intra-guild predation theory, where the quality of intra-guild prey and conspecifics is low relative to the quality of extra-guild prey (Polis, 1981; Polis et al., 1989), in this study, intra-guild prey seemed to be of equal or higher quality than extra-guild prey for both predators. Comparing the fitness measurements of predators predating on intra- and extra-guild prey, it was demonstrated that $A$. swirskii has higher oviposition rates and a faster development time on intra-guild prey ( $N$. cucumeris larvae) than on extra-guild prey (thrips). For N. cucumeris, oviposition rates on intra- and extra-guild prey were equal, but development time was faster on intra-guild prey (A. swirskii larvae). Usually, provision of abundant extra-guild prey has been demonstrated to decrease predation on intra-guild prey (Polis, 1981; Polis et al., 1989; Onzo et al., 2005; Zannou et al., 2005; Meszaros et al., 2007). However, both A. swirskii and $N$. cucumeris had a preference for intra-guild prey. Especially A. swirskii preferred N. cucumeris larvae over thrips even when both prey were abundant. This choice might be explained by the high food quality of intra-guild prey. In addition, in the observation choice trials, it was observed that thrips larvae showed defence behaviour, such as jerking the abdomen and producing a drop of rectal fluid in response to predator attack (Bakker \& Sabelis, 1989). Due to this defence behaviour, the thrips larvae often escaped predation. Intra-guild prey eggs were only predated in low numbers, resulting in low oviposition rates and low survival during development. In the choice experiments, adult A. swirskii almost never chose to predate on $N$. cucumeris eggs, while $N$. cucumeris adults successfully attacked A. swirskii eggs but had no preference for them. Both adult and juvenile predators were observed to have difficulties piercing the eggs of the other predator species with their mouthparts, which corresponds to reports for other phytoseiid mites (Schausberger, 1997; Schausberger \& Croft, 1999). From the observations, it seems both predatory mites predate on the first prey they can easily feed on, preferring intra-guild prey larvae because they do not exhibit defence behaviour like thrips larvae and are easier to feed on than intra-guild prey eggs.

Interestingly, the development time of $N$. cucumeris on thrips larvae was slow and variable, and survival to adult was low. To a lesser extend, the same trend could be observed for $A$. swirskii. These results can be explained by the difficulties that juvenile predators, especially larvae and protonymphs, had to capture the thrips, probably due to thrips defence behaviour (Bakker \& Sabelis, 1989). Similar results were obtained by Wimmer et al. (2008), where less than one third of the juvenile $A$. swirskii reached adulthood when fed thrips larvae. If thrips were killed by freezing just before offering them to the predators, A. swirskii and $N$. cucumeris development times were among the fastest (R. Buitenhuis, unpublished data). This indicates that, although first instar thrips larvae have high nutritional value for a developing predator, the difficulty of catching thrips makes them a less suitable food source. In other studies, juvenile phytoseiids have also been observed to have difficulties in overcoming the defences of even the smallest thrips, and may even be unable to attack thrips larvae and, therefore, need to rely on other food sources to complete their development (Sabelis \& van Rijn, 1997).

Intra-guild predation can influence coexistence of the two predator species and may affect thrips control in the greenhouse, as has been demonstrated for other biological control agents (Rosenheim \& Harmon, 2006; Vance-Chalcraft et al., 2007). Mutual intra-guild predation, as observed in this study, potentially increases the negative effects on pest control as compared to a system with one intra-guild predator and an intra-guild prey. However, there is also evidence that intra-guild predation may serve to stabilize the predator's population over time (Polis et al., 1989), for example by providing an alternative food source when prey is scarce. Predatory mites might experience less intra-guild interactions in the greenhouse or field than in laboratory experiments. Predators that engage in intra-guild predation may be able to coexist by having different foraging strategies or different distributions on the plant, and species dominance also may differ on different crop varieties (McMurtry 
\& Croft, 1997). For example, N. cucumeris distribution on sweet peppers was affected by other predators; in the presence of the predatory bug, Orius laevigatus (Fieber), virtually no mites occurred in the flowers (Weintraub et al., 2007). Also, habitat structure (Janssen et al., 2007) or leaf pubescence (Seelmann et al., 2007) can alter intra-guild predation interactions, and some species of phytoseiid mites tend to avoid patches with intra-guild predators using volatiles (Gnanvossou et al., 2003).

In conclusion, the results of this study indicate a high potential for negative interactions between $A$. swirskii and $N$. cucumeris when used together in biological control of thrips. There is need for further experiments investigating these intra-guild interactions on a larger scale in order to determine recommendations for the use of these two predators together in greenhouse crops.

\section{Acknowledgements}

We thank Wonhyo Lee and Yun Zhang for technical assistance. This research was supported by Flowers Canada (Ontario) and the Matching Investment Initiative of Agriculture and Agri-Food Canada.

\section{References}

Bakker, F.M. \& Sabelis, M.W. (1989) How larvae of Thrips tabaci reduce the attack succes of phytoseiid predators. Entomologia Experimentalis et Applicata 50, 47-51.

Croft, B.A. \& Croft, M.B. (1996) Intra- and interspecific predation among adult female Phytoseiid mites (Acari: Phytoseiidae): Effects on survival and reproduction. Environmental Entomology 25, 853-858.

Croft, B.A., Kim, S.S. \& Kim, D.I. (1996) Intra and interspecific predation on four life stage groups by adult females of Metaseiulus occidentalis, Typhlodromus pyri, Neoseiulus fallacis and Amblyseius andersoni. Experimental and Applied Acarology 20, 435-444.

Denno, R.F. \& Finke, D.L. (2006) Multiple predator interactions and food-web connectance: implications for biological control. pp. 45-70 in Brodeur, J. \& Boivin, G. (Eds) Trophic and Guild Interactions in Biological Control. Dordrecht, The Netherlands, Springer.

Finke, D.L. \& Denno, R.F. (2003) Intra-guild interaction relaxes natural enemy impacts on herbivore populations. Ecological Entomology 28, 67-73.

Gnanvossou, D., Hanna, R. \& Dicke, M. (2003) Infochemicalmediated intraguild interactions among three predatory mites on cassava plants. Oecologia 135, 84-90.

Helle, W. \& Sabelis, M.W. (1985) Spider Mites, their Biology, Natural Enemies and Control. Vol 1b, Amsterdam, The Netherlands, Elsevier.

Janssen, A., Pallini, A., Venzon, M. \& Sabelis, M.W. (1998) Behaviour and indirect interactions in food webs of plantinhabiting arthropods. Experimental and Applied Acarology 22, 497-521.

Janssen, A., Sabelis, M.W., Magalhães, S., Montserrat, M. \& van der Hammen, T. (2007) Habitat structure affects intraguild predation. Ecology 88, 2713-2719.

McMurtry, J.A. \& Croft, B.A. (1997) Life-styles of phytoseiid mites and their roles in biological control. Annual Review of Entomology 42, 291-321.
Messelink, G., Van Steenpaal, S. \& van Wensveen, W. (2005) Typhlodromips swirskii (Athias-Henriot) (Acari: Phytoseiidae): a new predator for thrips control in greenhouse cucumber. IOBC Bulletin 28, 183-186.

Messelink, G.J., Van Steenpaal, S.E.F. \& Ramakers, P.M.J. (2006) Evaluation of phytoseiid predators for control of western flower thrips on greenhouse cucumber. BioControl 51, 753-768.

Messelink, G., van Maanen, R., Van Steenpaal, S. \& Janssen, A. (2008) Biological control of thrips and whiteflies by a shared predator: Two pests are better than one. Biological Control 44, 372-379.

Meszaros, A., Tixier, M.-S., Cheval, B., Barbar, Z. \& Kreiter, S. (2007) Cannibalism and intraguild predation in Typhlodromus exhilaratus and T. phialatus (Acari: Phytoseiidae) under laboratory conditions. Experimental and Applied Acarology 41, 37-43.

Montserrat, M., Janssen, A., Magalhaes, S. \& Sabelis, M.W. (2006) To be an intra-guild predator or a cannibal: Is prey quality decisive? Ecological Entomology 31, 430-436.

Nomikou, M., Janssen, A., Schraag, R. \& Sabelis, M.W. (2001) Phytoseiid predators as potential biological control agents for Bemisia tabaci. Experimental and Applied Acarology 25, 271-291.

Onzo, A., Hanna, R., Negloh, K., Toko, M. \& Sabelis, M.W. (2005) Biological control of cassava green mite with exotic and indigenous phytoseiid predators - effects of intraguild predation and supplementary food. Biological Control 33, 143-152.

Overmeer, W.P.J. (1985) Rearing and Handling. pp. 161-170 in Helle, W. \& Sabelis, M.W. (Eds) Spider Mites: Their Biology, Natural Enemies and Control. Amsterdam, The Netherlands, Elseviers.

Polis, G.A. (1981) The evolution and dynamics of intraspecific predation. Annual Review of Ecology and Systematics 12, 225-251.

Polis, G.A. \& Holt, R.D. (1992) Intraguild predation: the dynamics of complex trophic interactions. Trends in Ecology and Evolution 7, 151-154.

Polis, G.A., Myers, C.A. \& Holt, R.D. (1989) The ecology and evolution of intraguild predation: potential competitors that eat each other. Annual Review of Ecology and Systematics 20, 297-330.

Prasad, R.P. \& Snyder, W.E. (2004) Predator inference limits fly egg biological control by a guild og ground-active beetles. Biological Control 31, 428-437.

Rasmy, A.H., Abou El-Ella, G.M. \& Hussein, H.E. (2004) Cannibalism and interspecific predation of the phytoseiid mite, Amblyseius swirskii. Journal of Pest Science 77, 23-25.

Robb, K.L. (1989) Analysis of Frankliniella occidentalis (Pergande) as a pest of floricultural crops in California. PhD thesis, University of California, Riverside, California, USA.

Rosenheim, J.A. \& Harmon, J.P. (2006) The influence of intraguild predation on the suppression of a shared prey population: an empirical reassessment. pp. 1-20 in Brodeur, J. \& Boivin, G. (Eds) Trophic and Guild Interactions in Biological Control. Dordrecht, The Netherlands, Springer.

Rosenheim, J.A., Kaya, H.K., Ehler, L.E., Marois, J.J. \& Jaffee, B.A. (1995) Intra-guild predation among biologicalcontrol agents: theory and evidence. Biological Control 5, 303-335.

Sabelis, M.W. \& van Rijn, P.C.J. (1997) Predation by insects and mites. pp. 259-354 in Lewis, T. (Ed) Thrips as Crop Pests. New York, USA, CAB International. 
Schausberger, P. (1997) Inter- and intraspecific predation on immatures by adult females in Euseius finlandicus, Typhlodromus pyri and Kampimodromus aberrans (Acari, Phytoseiidae). Experimental and Applied Acarology 21, 131-150.

Schausberger, P. (1999) Juvenile survival and development in Euseius finlandicus, Typhlodromus pyri and Kampimodromus aberrans (Acari: Phytoseiidae) feeding on conspecific and heterospecific immatures. Experimental and Applied Acarology 23, 297-307.

Schausberger, P. \& Croft, B.A. (1999) Predation on and discrimination between con- and heterospecific eggs among specialist and generalist phytoseiid mites (Acari: Phytoseiidae). Environmental Entomology 28, 523-528.

Schausberger, P. \& Croft, B.A. (2000) Cannibalism and intraguild predation among phytoseiid mites: are aggressiveness and prey preference related to diet specialization? Experimental and Applied Acarology 24, 709-725.

Seelmann, L., Auer, A., Hoffmann, D. \& Schausberger, P. (2007) Leaf pubescence mediates intraguild predation between predatory mites. Oikos 116, 807-817.

Symondson, W.O.C., Sunderland, K.D. \& Greenstone, M.H. (2002) Can generalist predators be effective biocontrol agents? Annual Review of Entomology 47, 561-594.

van Houten, Y.M., van Rijn, P.C.J., Tanigoshi, L.K., van Stratum, P. \& Bruin, J. (1995) Preselection of predatory mites to improve year-round biological control of western flower thrips in greenhouse crops. Entomologia Experimentalis et Applicata 74, 225-234.

van Houten, Y., Ostlie, M.L., Hoogerbrugge, H. \& Bolckmans, K. (2005) Biological control of western flower thrips in sweet pepper using the predatory mites Amblyseius cucumeris, Iphiseius degenerans, A. andersoni and A. swirskii. IOBC Bulletin 28, 283-286.

Vance-Chalcraft, H.D., Rosenheim, J.A., Vonesh, J.R., Osenberg, C.W. \& Sih, A. (2007) The influence of intraguild predation on prey suppression and prey release: a meta-analysis. Ecology 88, 2689-2696.

Walzer, A. \& Schausberger, P. (1998) Predation preference and discrimination between con- and heterospecific prey by the phytoseiid mites Phytoseiulus persimilis and Neoseiulus californicus. BioControl 43, 469-478.

Walzer, A. \& Schausberger, P. (1999) Cannibalism and interspecific predation in the phytoseiid mites Phytoseiulus persimilis and Neoseiulus californicus: Predation rates and effects on reproduction and juvenile development. Biocontrol 43, 457-468.

Weintraub, P.G., Kleitman, S., Alchanatis, V. \& Palevsky, E. (2007) Factors affecting the distribution of a predatory mite on greenhouse sweet pepper. Experimental and Applied Acarology 42, 23-35.

Wimmer, D., Hoffmann, D. \& Schausberger, P. (2008) Prey suitability of western flower thrips, Frankliniella occidentalis, and onion thrips, Thrips tabaci, for the predatory mite Amblyseius swirskii. Biocontol Science and Technology 18, 541-550.

Zannou, I.D., Hanna, R., Moraes, G.J.D. \& Kreiter, S. (2005) Cannibalism and interspecific predation in a phytoseiid predator guild from cassava fields in Africa: evidence from the laboratory. Experimental and Applied Acarology 37, 27-42. 